\title{
The Sympathetic and Parasympathetic Contributions to the Cardiac Plexus: a Fetal Study
}

\author{
Contribuciones Simpáticas y Parasimpáticas al Plexo Cardíaco: Estudio Fetal
}

\author{
B. Z. De Gama; L. Lazarus; P. Partab \& K. S. Satyapal
}

DE GAMA, B. Z.; LAZARUS, L.; PARTAB, P. \& SATYAPAL, K. S. The sympathetic and parasympathetic contributions to the cardiac plexus: a fetal study. Int. J. Morphol., 30(4):1569-1576, 2012.

SUMMARY: The cardiac plexus is formed by sympathetic nerves originating from the superior, middle, inferior cervical or cervicothoracic ganglia as well as from the first to the fifth thoracic ganglia. Furthermore, the vagus nerve and its counterpart, the recurrent laryngeal nerve supply the cardiac plexus with parasympathetic cardiac nerves. This investigation aimed to review and record the medial contributions of the cervical ganglia, first to fifth thoracic ganglia and medial contributions of the vagus and recurrent laryngeal nerves to the cardiac plexus. The study involved bilateral micro-dissection of forty cadaveric fetal specimens ( $\mathrm{n}=80$ ). The origins of sympathetic contributions to the cardiac plexus were described as either ganglionic, inter-ganglionic or from both the ganglion and the inter-ganglionic sympathetic chain. The number of cervical sympathetic ganglia varied from two to five in this study; the superior cervical ganglion was constant while the middle cervical, vertebral, inferior cervical or cervicothoracic ganglia were variable. The prevalence of cardiac nerves were as follows: superior cervical cardiac nerve (95\%); middle cervical cardiac nerve (73\%); vertebral cardiac nerve $(41 \%)$; inferior cervical cardiac nerve $(21 \%)$ and cervicothoracic cardiac nerve $(24 \%)$. This investigation records the thoracic caudal limit of the thoracic sympathetic contributions to the cardiac plexus as the T5 ganglion. The findings of this study highlight the importance of understanding the medial sympathetic contributions and their variations to the cardiac plexus as this may assist surgeons during minimal access surgical procedures, sympathectomies, pericardiectomies and in the management of diseases like Raynaud's Phenomenon and angina pectoris.

KEY WORDS: Cardiac plexus; Sympathetic; Parasympathetic; Vagus nerve; Superficial cardiac plexus; Deep cardiac plexus.

\section{INTRODUCTION}

The cardiac plexus is formed by "mixed autonomic nerves" that are described in terms of superficial and deep components, with the superficial located below the aortic arch, anterior to the pulmonary artery, and the deep located posterior to the aortic arch and anterior to the tracheal bifurcation (above the division of the pulmonary trunk) (Standring et al., 2008). Mizeres, in 1972, reported that the cardiac plexus lay on the anterior and posterior walls of the pulmonary trunk and consisted of subsidiary plexuses to great vessels and walls of the heart. These subsidiary plexuses were named pulmonary, atrial, coronary plexuses and plexus on the arch of aorta (Mizeres, 1972). However, Kawashima (2005) referred to a right cardiac plexus that surrounded the brachiocephalic trunk and a left cardiac plexus that surrounded the arch of aorta. The cardiac sympathetic nerves arise from the medial aspect of the cervical and upper thoracic parts of the sympathetic chain and contribute the majority of branches to the cardiac plexus. Several authors have described contributions of the cervical ganglia as cervical cardiac nerves (CCNs) to the cardiac plexus (Kuntz \& Morehouse, 1930; Kalsey et al., 2000; Pather et al., 2003) whilst only a few report on the thoracic cardiac nerves (TCNs) to this plexus (Kuntz \& Morehouse; Groen et al., 1987). The CCNs arise from the superior (SCG), middle (MCG) and inferior (ICG) or cervicothoracic (CTG) cervical ganglia and the TCNs arise from the thoracic sympathetic chain (Standring et al.). Furthermore, Becker \& Grunt (1957) state that the vertebral ganglion (VG) (i.e. a ganglion located in relation to the vertebral artery) and the high or low MCG (i.e. ganglia located as high as the third cervical vertebra or as low as the seventh cervical vertebra, respectively) may also be present in the cervical sympathetic chain. According to standard anatomical textbooks, the TCNs arise from the upper four or five thoracic ganglia (Standring et al.). 
However, other studies have found the limit of these to vary from the CTG (Randall \& Armour, 1977) to the seventh thoracic (T7) ganglion (Saccommano, 1943).

It has been reported by several authors that the parasympathetic nerve supply to the cardiac plexus originates from the vagus nerve (VN) via its superior and inferior branches as well as from its counterpart, the recurrent laryngeal nerve (RLN) (Mizeres; Kawashima; San Mauro et al.). Mizeres described cervical cardiac branches (these arose from any part of the cervical part of the $\mathrm{VN}$ as far inferiorly as the lower border of the sixth cervical vertebra), Kawashima described these as originating from the upper portion of the RLN while San Mauro et al. named these superior cardiac nerves originating from superior and inferior laryngeal nerves. Cervicothoracic branches, as described by Mizeres, arose from the RLN near its origin and from the vagal trunk at the levels of the seventh cervical and the first thoracic vertebrae while Kawashima termed these the inferior branches originating from the RLN. San Mauro et al. termed these inferior cardiac nerves. Branches arising from the thoracic vagal trunk between the level of the lower border of the first thoracic vertebra and the pulmonary hilum were termed thoracic cardiac branches by Mizeres and Kawashima described these as branches originating from the lower portion of RLN. However, San Mauro et al. did not describe these thoracic branches.

Variations in the sympathetic and parasympathetic contributions to the cardiac plexus have been previously reported by Kawashima and San Mauro et al. An understanding of cardiac nerves is clinically important as these nerves are capable of capturing changes in tissue ischemia and translating them into referred pain sensations (San Mauro et al.). Khogali et al. (1999), was successful in interrupting the pain pathway in a limited second to fourth thoracic ganglionectomy to relieve pain at rest in patients with intractable angina pectoris. This highlights the importance of medial sympathetic contributions to the cardiac plexus and their relevance to surgical procedures such as sympathectomies, pericardiectomies and in the management of diseases like Raynaud's phenomenon and angina pectoris (Kalsey et al.; Zhang et al., 2009).

\section{MATERIAL AND METHOD}

Forty fetal specimens (gestational age range: 16-30 weeks) were obtained from the Discipline of Clinical Anatomy at the University of KwaZulu-Natal, Durban, South Africa. The cervical and thoracic components of the sympathetic chain (up to the eighth thoracic vertebral level) and the VN and RLN were bilaterally macro and microdissected using a Stemi DV4 stereomicroscope (Carl Zeiss Inc., Germany). Ethical clearance was obtained from the University Bio-Medical Research and Ethics Committee (Ethical clearance number: BF 152/07).

Thoracic dissection was performed prior to cervical dissection. A midline vertical skin incision was made from the jugular notch (at the level between the second and third thoracic vertebrae) to the xiphisternal junction (at the level between the tenth and eleventh thoracic vertebrae) and two transverse incisions were subsequently made viz. (i) from jugular notch to halfway of the arm and (ii) from xiphoid process to the midaxillary line (MAL). The skin was reflected from medial to lateral and detached at the MAL. All muscles attached to the anterior thoracic wall were detached from the rib cage. The clavicle was cut at its mid-length and a transverse cut across the sternum and costal cartilages at the level of the eighth intercostal space was made. All intervening intercostal muscles, vessels and rib cage were cut and removed. All surrounding tissue and the supra-pleural membrane overlying the sympathetic chain were carefully removed from the first rib to the costo-diaphragmatic recess (at the level of the tenth and eleventh thoracic vertebrae).

In the cervical dissection, a midline vertical incision from the mental protuberance to the jugular notch (at the level between the second and third thoracic vertebrae) was made and a lateral incision from the angle of the mandible (at the level of second cervical vertebra) along the anterior border of the trapezius to the first transverse incision of the thoracic dissection was also made. The skin and fascia were reflected from medial to lateral to the latter vertical incision. The sternocleidomastoid and strap muscles of the neck were detached and removed with the major venous structures viz. subclavian and brachiocephalic veins to expose the brachiocephalic trunks and subclavian arteries. The cervical sympathetic trunk and ganglia were then traced from the base of the skull to the thoracic inlet to identify medial branches to the cardiac plexus. The brachiocephalic trunk and subclavian artery on the right were further excised to view ganglia and contributions to the cardiac plexus while the common carotid and the subclavian arteries were further excised on the left to view the same.

The sympathetic trunk, vagus and recurrent laryngeal nerves were identified and their medial contributions to the cardiac plexus exposed, traced and recorded. For ease of reference, the nomenclature used in this study to describe these branches from the former origins to the cardiac plexus is depicted in a glossary of terms in Table I. 
Table I. Glossary of terms.

\begin{tabular}{|c|c|}
\hline Abbreviation & Term \\
\hline MAL & Midaxillary line \\
\hline SCG & Superior cervical ganglion \\
\hline MCG & Middle cervical ganglion \\
\hline VG & Vertebral ganglion \\
\hline ICG & Inferior cervical ganglion \\
\hline CTG & Cervico-thoracic ganglion \\
\hline $\mathrm{T}_{\mathrm{I}} \mathrm{G}$ & First thoracic ganglion \\
\hline $\mathrm{T}_{2} \mathrm{G}$ & Second thoracic ganglion \\
\hline $\mathrm{T}_{3} \mathrm{G}$ & Third thoracic ganglion \\
\hline $\mathrm{T}_{4} \mathrm{G}$ & Fourth thoracic ganglion \\
\hline $\mathrm{T}_{5} \mathrm{G}$ & Fifth thoracic ganglion \\
\hline $\mathrm{SCCN}$ & Superior cervical cardiac nerve \\
\hline $\mathrm{MCCN}$ & Middle cervical cardiac nerve \\
\hline $\mathrm{VCN}$ & Vertebral cardiac nerve \\
\hline $\mathrm{ICCN}$ & Inferior cervical cardiac nerve \\
\hline CTCN & Cervico-thoracic cardiac nerve \\
\hline $\mathrm{TCN}_{1}$ & First thoracic cardiac nerve \\
\hline $\mathrm{TCN}_{2}$ & Second thoracic cardiac nerve \\
\hline $\mathrm{TCN}_{3}$ & Third thoracic cardiac nerve \\
\hline $\mathrm{TCN}_{4}$ & Fourth thoracic cardiac nerve \\
\hline $\mathrm{TCN}_{5}$ & Fifth thoracic cardiac nerve \\
\hline $\mathrm{CVCN}$ & Cervical vagal cardiac nerves \\
\hline SCVCN & Superior cervical vagal cardiac nerve \\
\hline MCVCN & Middle cervical vagal cardiac nerve \\
\hline ICVCN & Inferior cervical vagal cardiac nerve \\
\hline TVCN & Thoracic vagal cardiac nerves \\
\hline RLN & Recurrent laryngeal nerve \\
\hline RLCN & Recurrent laryngeal cardiac nerve \\
\hline SCP & Superficial cardiac plexus \\
\hline $\mathrm{DCP}$ & Deep cardiac plexus \\
\hline
\end{tabular}

\section{RESULTS}

Incidence of cervical ganglia. The SCG was a constant entity and was observed in all specimens i.e. $80 / 80(100 \%)$. The prevalence of the MCG, ICG and CTG were 63/80 (79\%), 36/80 (45\%) and 38/80 (48\%), respectively. Separate VG (classified as the ganglion located on the anterior surface of the vertebral artery (Kawashima) were observed in 41/80 (51\%) of the cases. Additionally, double MCG (classified as ganglia located in the cervical sympathetic chain between the SCG and the ICG or CTG were identified). The location and description of the MCG was based on Becker \& Grunt's classification which described the MCG in relation to the

inferior thyroid artery (ITA) viz. 'high' MCG located above the ITA; 'normal' MCG lying on the ITA; 'low' MCG located below ITA. These (i.e. double ganglia) were observed in 3/ $80(4 \%)$ of the specimens (Table II).

Table II. Incidence of cervical ganglia.

\begin{tabular}{lcc}
\hline Ganglion & Foetuses $(\mathbf{n = 8 0})$ & Total $(\boldsymbol{\%})$ \\
\hline SCG & 80 & 100 \\
MCG & 63 & 79 \\
VG & 41 & 51 \\
ICG & 36 & 45 \\
CTG & 38 & 48 \\
\hline
\end{tabular}

\section{Sympathetic Cardiac nerves}

- Cervical cardiac nerves. The CCNs were described as nerves traced to the cardiac plexus that originated from the cervical sympathetic ganglia or inter-ganglionic portion of the cervical sympathetic chain or from both the cervical sympathetic ganglia and inter-ganglionic chain (Fig. 1). The incidences of the CCNs originating from the cervical sympathetic ganglia were as follows: (a) superior cervical cardiac nerves (SCCNs) from the SCG, inter-ganglionic chain and both in 76/80 (95\%) (Fig. 2); (b) middle cervical cardiac nerves (MCCNs) from the MCG, inter-ganglionic chain and both in 58/80 (73\%) (Fig. 3); (c) vertebral cardiac nerves (VCNs) from the VG only in 33/80 (41\%) (Fig. 4); (d) inferior cervical cardiac nerves (ICCNs) from the ICG only in $17 / 80$ (21\%) (Fig. 5) and (e) cervicothoracic cardiac nerves (CTCNs) from the CTG only in 19/80 (24\%) (Table III; Fig. 2). Contributions from the double MCG were from both the ganglia and inter-ganglionic chains.

Table III. Incidence and origin of cardiac nerves originating from the cervical and thoracic sympathetic ganglia or interganglionic portions or both of sympathetic chain.

\begin{tabular}{lcccc}
\hline Nerve & $\begin{array}{c}\text { Incidence } \\
(\%)\end{array}$ & \multicolumn{3}{c}{ Origin (\%) } \\
\cline { 3 - 5 } & & Ganglionic & Interganglionic & Both \\
\hline $\mathrm{SCCN}$ & 95 & 36 & 14 & 45 \\
$\mathrm{MCCN}$ & 73 & 61 & 1 & 10 \\
$\mathrm{VCN}$ & 41 & 41 & - & - \\
$\mathrm{ICCN}$ & 21 & 21 & - & - \\
$\mathrm{CTCN}$ & 24 & 24 & - & - \\
$\mathrm{TCN}$ & 40 & 40 & - & - \\
$\mathrm{TCN}_{2}$ & 28 & 25 & 3 & - \\
$\mathrm{TCN}_{3}$ & 19 & 19 & - & - \\
$\mathrm{TCN}_{4}$ & 11 & 10 & 1 & - \\
$\mathrm{TCN}_{5}$ & 4 & 4 & - & - \\
\hline
\end{tabular}




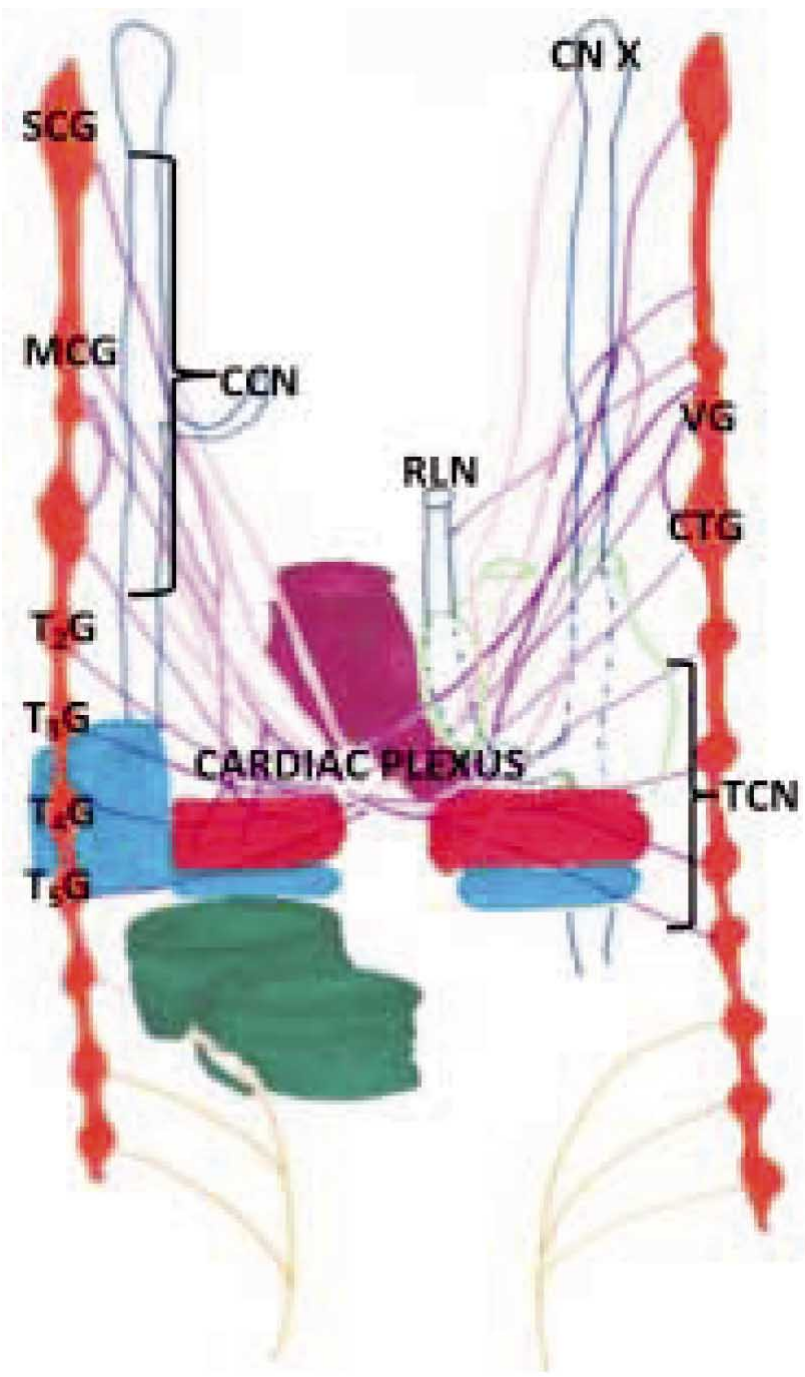

Fig. 1. Diagrammatic representation of the origin of sympathetic and parasympathetic contributions to the cardiac plexus.

Key: $\mathrm{CCN}=$ Cervical cardiac nerves; $\mathrm{CN} X=$ Vagus nerve; $\mathrm{SCG}=$ Superior cervical ganglion; $\mathrm{MCG}=$ Middle cervical ganglion; $\mathrm{MCCN}=$ Middle cervical cardiac nerve; $\mathrm{VG}=$ Vertebral ganglion; $\mathrm{CTG}=\mathrm{Cervicothoracic}$ ganglion; $\mathrm{T}_{2} \mathrm{G}=$ Second thoracic ganglion; $\mathrm{T}_{3} \mathrm{G}=$ Third thoracic ganglion; $\mathrm{T}_{4} \mathrm{G}=$ Fourth thoracic ganglion; $\mathrm{T}_{5} \mathrm{G}=$ Fifth thoracic ganglion; $\mathrm{TCN}=$ Thoracic cardiac nerve; RLN= Recurrent laryngeal nerve.

- Thoracic cardiac nerves. TCNs were defined as nerves traced to the cardiac plexus that originated from the thoracic sympathetic ganglia or inter-ganglionic portion of the thoracic sympathetic chain. The incidences of the TCNs originating from the thoracic sympathetic ganglia were as follows: (a) first thoracic cardiac nerve $\left(\mathrm{TCN}_{1}\right)$ from the first ganglion ( $\mathrm{T}_{1} \mathrm{G}$ ) only in 32/80 (40\%); (b) second thoracic cardiac nerve $\left(\mathrm{TCN}_{2}\right)$ from the second thoracic ganglion $\left(\mathrm{T}_{2} \mathrm{G}\right)$ and inter-ganglionic chain in 22/80 (28\%); (c) third thoracic cardiac nerve $\left(\mathrm{TCN}_{3}\right)$ from the third thoracic

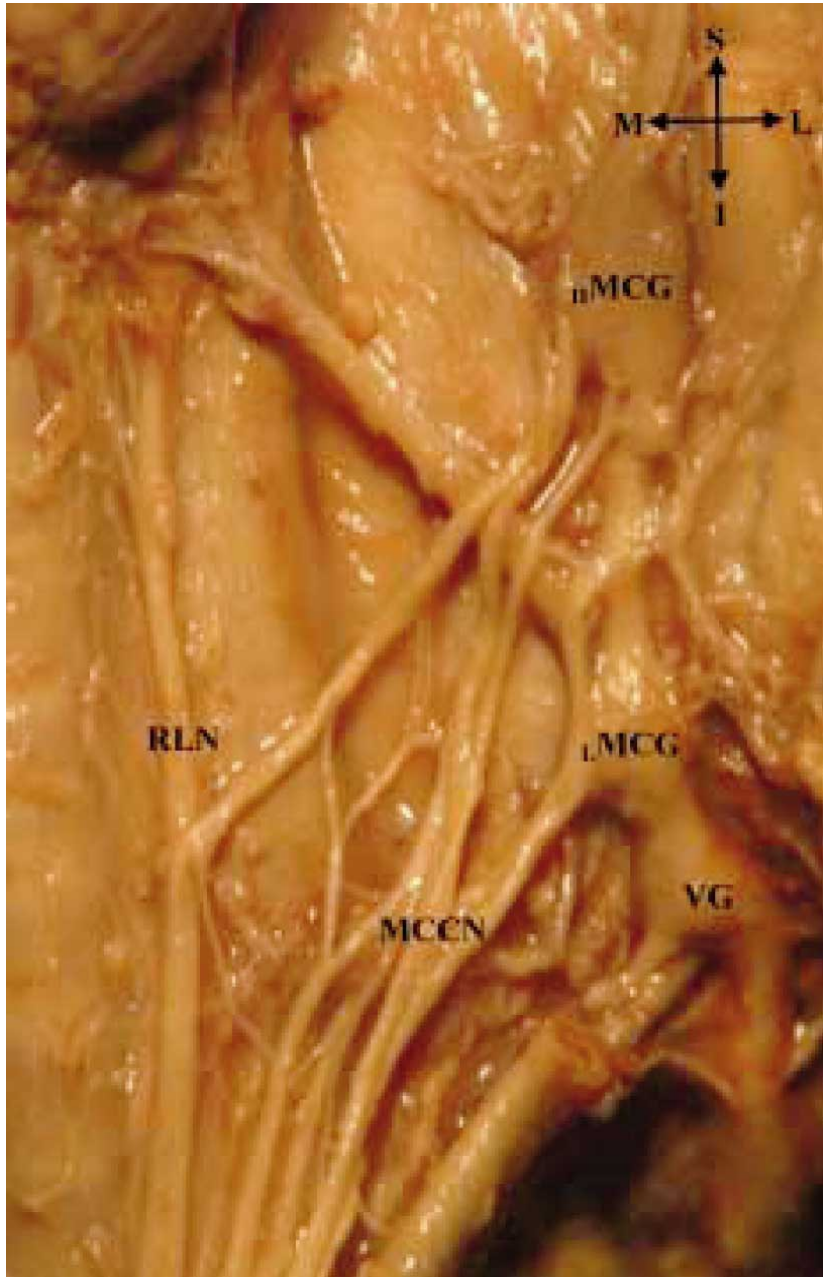

Fig. 2. Left oblique view of the neck demonstrating a double MCG with ganglionic, interganglionic and both ganglionic and interganglionic origins.

Key: $\mathrm{MCG}=$ Middle cervical ganglion; $\mathrm{HMCG}=$ High middle cervical ganglion; $\mathrm{LMCG}=$ Low middle cervical ganglion; $\mathrm{MCCN}=$ Middle cervical cardiac nerve; RLN= Recurrent laryngeal cardiac nerve; VG= Vertebral ganglion.

ganglion $\left(\mathrm{T}_{3} \mathrm{G}\right)$ only in $15 / 80(19 \%)$; (d) fourth thoracic cardiac nerve $\left(\mathrm{TCN}_{4}\right)$ from the fourth thoracic ganglion $\left(\mathrm{T}_{4} \mathrm{G}\right)$ and inter-ganglionic chain in 9/80 (11\%); (e) fifth thoracic cardiac nerve $\left(\mathrm{TCN}_{5}\right)$ from the fifth thoracic ganglion $\left(\mathrm{T}_{5} \mathrm{G}\right)$ only in 3/80 (4\%) (Table III; Fig. 3).

Parasympathetic cardiac nerves. The VN also contributed to the formation of the cardiac plexus. Vagal cardiac branches were identified as superior (i.e. the branch that left the $\mathrm{VN}$ in the upper part of the neck to reach any part of the cardiac plexus), middle (i.e. the branch that arose from the lower third of the $\mathrm{VN}$ in the neck that reached any part of the cardiac plexus) and inferior (the branch that arose 


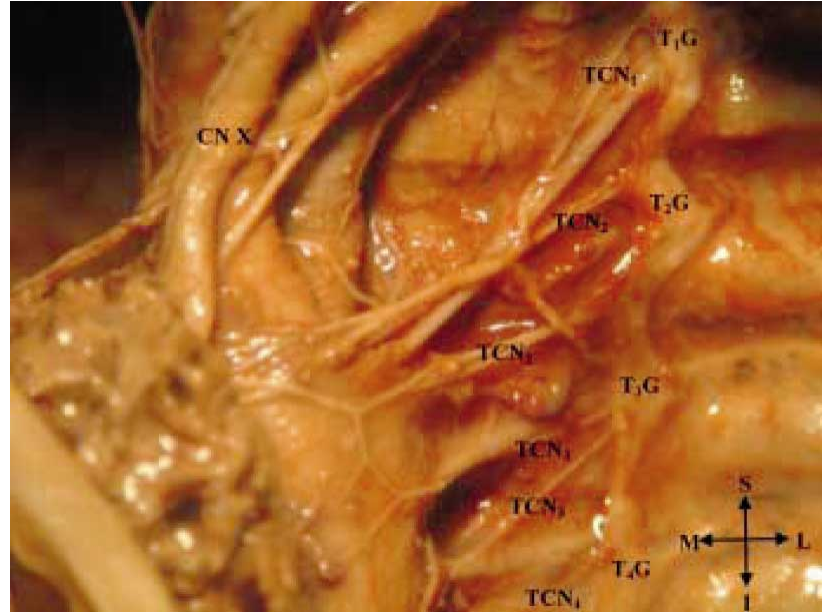

Fig. 3. Left supero-lateral view of the thorax demonstrating the origin of thoracic cardiac nerves from $\mathrm{T} 1$ to $\mathrm{T} 4$ thoracic ganglia. Key: CN X= Vagus nerve; $\mathrm{TCN}_{1}=$ First thoracic cardiac nerve; $\mathrm{TCN}_{2}=$ Second thoracic cardiac nerve; $\mathrm{TCN}_{3}=$ Third thoracic cardiac nerve; $\mathrm{TCN}_{4}=$ Fourth thoracic cardiac nerve; $\mathrm{T}_{1} \mathrm{G}=$ First thoracic ganglion; $\mathrm{T}_{2} \mathrm{G}=$ Second thoracic ganglion; $\mathrm{T}_{3} \mathrm{G}=$ Third thoracic ganglion; $\mathrm{T}_{4} \mathrm{G}=$ Fourth thoracic ganglion.

from the $\mathrm{VN}$ at the cervicothoracic inlet or within the upper thorax to reach any part of the cardiac plexus) cervical vagal cardiac nerves $(\mathrm{CVCN})$ depending on the level at which they originated from the VN. Thoracic vagal cardiac nerves (TVCN) were defined as branches that arose from the VN below the cervicothoracic inlet to reach the deep part of the cardiac plexus. The incidences of vagal cardiac nerves were as follows: (a) superior cervical vagal cardiac nerve (SCVCN) 19/80 (24\%); (b) middle cervical vagal cardiac nerve (MCVCN) 29/80 (36\%); (c) inferior cervical vagal cardiac nerve (ICVCN) 56/80 (70\%); (d) TVCNs 40/80 (50\%) (Table IV; Fig. 4).

Recurrent laryngeal cardiac nerves (RLCN) were described as nerves that arose from any part of the RLN to reach the DCP. The RLCNs had an incidence of 25/80 (31\%) (Table IV).

Cardiac plexus. The superficial cardiac plexus (SCP) and deep cardiac plexus (DCP) received variable contributions from the sympathetic and parasympathetic nerves. The cervical sympathetic contributions were found to inosculate with each other before reaching either plexus.

SCP. The SCP was located in relation to the arch of aorta and the left pulmonary artery on the left side in 34/40 (85\%) and related to the ascending aorta and brachiocephalic trunk $(6 / 40 ; 15 \%)$ on the right side (Fig. 5). The SCP received

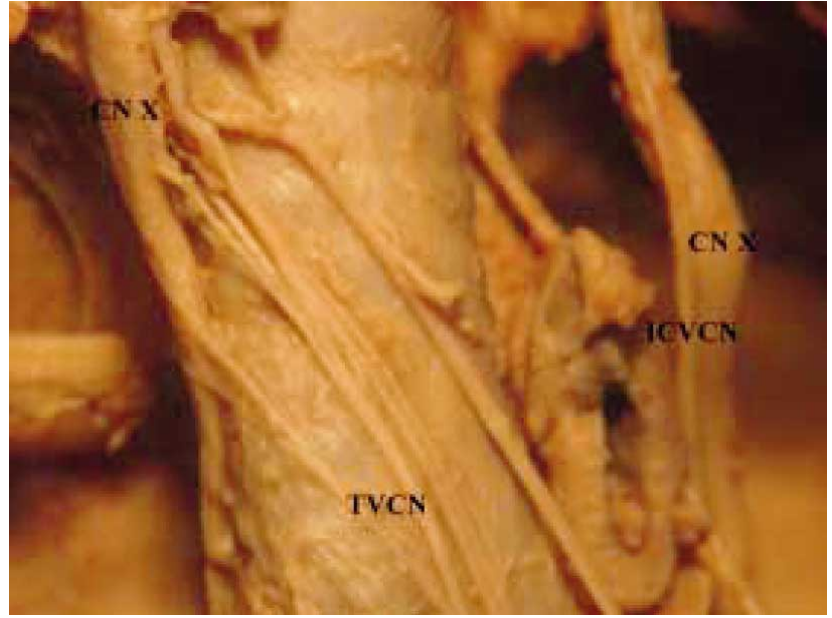

Fig. 4. Right supero-lateral view of the vagus nerve demonstrating the thoracic vagal cardiac nerves.

Key: CN X= Vagus nerve; ICVCN= Inferior cervical vagal cardiac nerve; TVCN= Thoracic vagal cardiac nerve.

Table IV. Incidence of parasympathetic contributions to cardiac plexus.

\begin{tabular}{lccc}
\hline Nerve & Incidence (\%) & Right $(\mathbf{n}=\mathbf{4 0})$ & Left $(\mathbf{n = 4 0})$ \\
\hline SCVCN & 24 & 8 & 11 \\
MCVCN & 36 & 14 & 15 \\
ICVCN & 70 & 31 & 25 \\
TVCN & 50 & 40 & - \\
RLCN & 31 & 22 & 3 \\
\hline
\end{tabular}

sympathetic contributions from the SCCN $35 / 80$ (88\%); MCCN 17/80 (43\%); VCN 7/80 (18\%) and CTCN 2/80 (3\%), respectively. The SCP also received parasympathetic contributions from the vagus nerve in $38 / 80$ (48\%) of the specimens (Table V).

Table V. Percentage contributions to the SCP.

\begin{tabular}{lccc}
\hline Nerve & Incidence (\%) & Right $(\mathbf{n}=\mathbf{4 0})$ & Left $(\mathbf{n = 4 0})$ \\
\hline SCCN $^{*}$ & 88 & 3 & 32 \\
MCCN $^{*}$ & 43 & 2 & 15 \\
VCN $^{*}$ & 18 & 3 & 4 \\
CTCN $^{*}$ & 3 & 0 & 2 \\
Vagus** & 48 & 5 & 33 \\
\hline
\end{tabular}

*= Sympathetic, $* *=$ Parasympathetic

DCP . The DCP was located posterior to the arch of aorta and anterior to the tracheal bifurcation in $80 / 80(100 \%)$ of the specimens (Fig. 6). The DCP received contributions from 


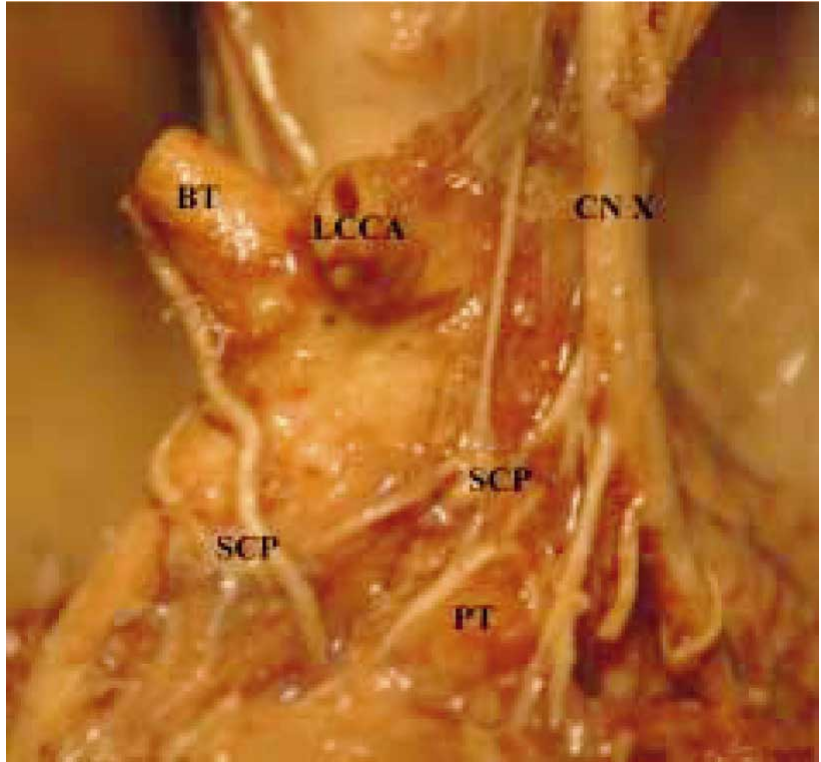

Fig. 5. Anterior view of the thorax demonstrating a SCP on the brachiocephalic trunk and ascending aorta.

Key: $\mathrm{BT}=$ Brachiocephalic trunk; $\mathrm{SCP}=$ Superficial cardiac plexus; $\mathrm{LCCA}=$ Left common carotid artery; $\mathrm{CN} \mathrm{X}=$ Vagus nerve; $\mathrm{PT}=$ Pulmonary trunk.

the cervical component of the sympathetic chain via the SCCN $66 / 80(83 \%)$, MCCN 56/80 (70\%), VCN 26/80 (33\%), ICCN $17 / 80(21 \%)$ and CTCN 17/80 (21\%). The contribution of the TCNs to the DCP were as follows: $\mathrm{TCN}_{1} 32 / 80(40 \%), \mathrm{TCN}_{2}$ $22 / 80$ (28\%), $\mathrm{TCN}_{3} 14 / 80(18 \%), \mathrm{TCN}_{4} 9 / 80(11 \%)$ and $\mathrm{TCN}_{5}$ $3 / 80(4 \%)$ of specimens, respectively (Table VI, Fig. 6).

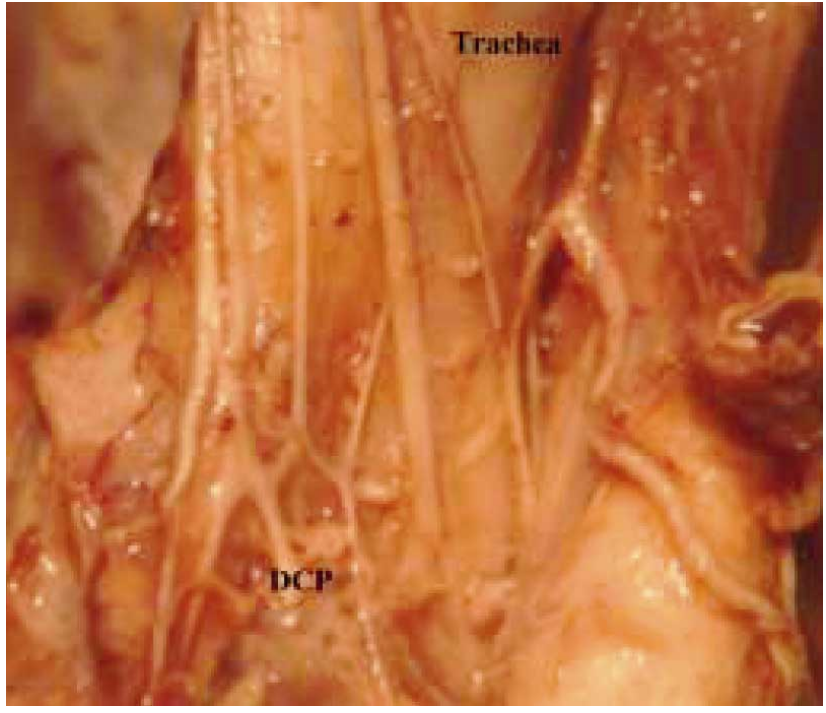

Fig. 6. Anterior view of the DCP. Key: $\mathrm{DCP}=$ Deep cardiac plexus.

The DCP also received parasympathetic contributions from the superior (SCVCN), middle (MCVCN) and inferior (ICVCN) cervical vagal cardiac nerves in 10/80 (13\%), 13/ $80(33 \%)$ and $34 / 80(43 \%)$ of the specimens, respectively. The TVCN and RLCNs contributed to the DCP in 40/80 (50\%) and 28/80 (31\%) of cases, respectively (Table VI, Fig. 6).

Table VI. Percentage contributions to the DCP.

\begin{tabular}{lcccc}
\hline Origin of contribution & Contributions & Incidence (\%) & Right $(\mathbf{n}=\mathbf{4 0})$ & Left $(\mathbf{n}=\mathbf{4 0})$ \\
\hline SCG & SCCN & 83 & 37 & 29 \\
MCG & $\mathrm{MCCN}$ & 70 & 25 & 31 \\
VG & VCN & 33 & 10 & 16 \\
ICG & ICCN & 21 & 8 & 9 \\
CTG & $\mathrm{CTCN}$ & 21 & 6 & 11 \\
$\mathrm{~T}_{1} \mathrm{G}$ & $\mathrm{TCN}_{1}$ & 40 & 10 & 22 \\
$\mathrm{~T}_{2} \mathrm{G}$ & $\mathrm{TCN}_{2}$ & 28 & 7 & 15 \\
$\mathrm{~T}_{3} \mathrm{G}$ & $\mathrm{TCN}_{3}$ & 18 & 6 & 8 \\
$\mathrm{~T}_{4} \mathrm{G}$ & $\mathrm{TCN}_{4}$ & 11 & 3 & 6 \\
$\mathrm{~T}_{5} \mathrm{G}$ & $\mathrm{TCN}_{5}$ & 4 & 3 & 0 \\
$\mathrm{VN}$ & $\mathrm{SCVCN}_{\mathrm{N}}$ & 13 & 8 & 2 \\
$\mathrm{VN}$ & $\mathrm{MCVCN}$ & 16 & 11 & 2 \\
VN & $\mathrm{ICVCN}$ & 43 & 31 & 3 \\
VN & $\mathrm{TVCN}$ & 50 & 40 & 0 \\
RLN & $\mathrm{RLCN}$ & 31 & 22 & 3 \\
\hline
\end{tabular}




\section{DISCUSSION}

A review and description of the cervical sympathetic chain revealed that this component of the sympathetic chain consisted of a series of ganglia that were variable in number and position (Kadowaki \& Levett, 1986). A constant incidence of $100 \%$ for the SCG is recorded in the literature (Ellison \& Williams, 1969; Kawashima; Standring et al.), while many authors describe varying incidences of the MCG, VG, ICG or CTG (Becker \& Grunt; Ellison \& Williams; Kalsey et al.; Kawashima). This study records the SCG to be present in all specimens whilst the MCG, VG, ICG and CTG had incidences of $79 \%, 51 \%, 45 \%$ and $48 \%$, respectively. This study also reports five ganglia (viz. SCG, high and low MCG, VG, ICG or CTG) present in the cervical sympathetic chain in $2 \%$ of cases. Double MCG (viz. high, 5\% and low, 3\%) were recorded in $4 \%$ of specimens in our study, concurring with Kalsey et al. The VG had an incidence of $48 \%$ in our specimens which compared favourably with the $55.3 \%$ in the study reported by Becker \& Grunt in 1957; however this differed widely from the $94.4 \%$ reported in the study conducted by Kawashima in 2005.

Our study also recorded an incidence of $45 \%$ for the ICG which differed with that reported by Becker \& Grunt $(62.3 \%)$ whilst the incidence of CTG (48\%) differed widely from that reported by Kawashima (13.9\%) and Pather et al. (2006) (16\%).

In this study the cardiac sympathetic nerves were described as (i) ganglionic when they originated from the cervical and thoracic ganglia; (ii) interganglionic when they originated from the interganglionic chain in the cervical and thoracic regions of the sympathetic chain and (iii) as both when they originated from the ganglia and the interganglionic chain. Incidences of $92 \%, 65 \%, 21 \%$ and $21 \%$ were recorded for the SCCN, MCCN, ICCN and CTCN, respectively. Our investigation also records a $\mathrm{VCN}$ in $39 \%$ of the specimens; this was only described by Kalsey et al., in $60 \%$ of animal specimens.

Previous studies have detailed varying descriptions of the cardiac plexus. Romanes (1968) described this plexus situated on the bifurcation of the trachea, made up of sympathetic and parasympathetic fibres. Mizeres described the cardiac plexus lying on the anterior and posterior walls of the bifurcation of the pulmonary trunk, consisting of subplexuses viz. pulmonary, atrial, coronary and the plexus on the arch of aorta. Hollinshead (1968) stated that the innervation of the heart is from the cardiac plexus which received sympathetic and vagal branches and gave off two coronary plexuses and two atrial plexuses.
This study describes the cardiac plexus in terms of its two components viz. superficial and deep parts, as described in current standard anatomical texts (Standring et al.). The SCP was found to be located inferior to the aortic arch and closely related to the right pulmonary artery, this corroborated the findings of San Mauro et al. The contributions to the formation of the SCP were variable. These were found to originate from any part of the cervical sympathetic chain viz. from the SCG 76\%; MCG 68\%, ICG 2\% and CTG 8\%. The $\mathrm{SCP}$ also received contributions from the middle and inferior cervical branches of VN. Our study appears unique in that it describes contributions from the MCVCN to the SCP. These were identified on both the right and left sides with incidences of $35 \%$ and $38 \%$, respectively. Previous literature states that the left superior and two inferior branches of $\mathrm{VN}$ contribute to the SCP.

The DCP was found to be constantly located posterior to the arch of aorta, anterior to the tracheal bifurcation and superior to the division of the pulmonary trunk (Standring et al.; San Mauro et al.). The description of the nerves contributing to the formation of the DCP is ambiguous in the literature. The DCP was formed by contributions from cervical (viz. SCG, MCG, ICG/CTG), thoracic ganglia (viz. $1^{\text {st }}$, $2^{\text {nd }}, 3^{\text {rd }}, 4^{\text {th }}$ and $\left.5^{\text {th }}\right), \mathrm{VN}$ and RLN in the specimens studied; this corroborated the study by Mizeres. The literature cited describes varying thoracic ganglionic or inter-ganglionic limits of contributions to the DCP viz. CTG (Randall \& Armour), T2 (Perman, 1924), T4 (Mitchell, 1953; Mizeres), T4-T5 (Fukuyama, 1982; San Mauro et al.); T5 (Kuntz \& Morehouse, 1930; Ellison \& Williams), T5-T6 (Pather et al., 2006); T6T7 (Saccommanno) and T7 (Kawashima). Our study found no contributions below the T5 ganglion disagreeing with Saccomano and Kawashima.

These findings may be of interest to clinicians during the treatment of patients with intractable angina that are unsuitable for conventional revascularization as this study provides clarity on the cardiac nerve contributions to the cardiac plexus. Excision of the sympathetic chain with histological confirmation during video assisted thoracic sympathectomy is a safe and effective method in treating hyperhidrosis, facial flushing and intractable angina with good long term results and satisfaction (Rathinam et al., 2008).

CONCLUSION. This study confirms the locations of the SCP and DCP. The SCP also received contributions from the right cervical sympathetic chain and vagus nerve. The DCP is formed by contributions from the right and left cervical and thoracic sympathetic chains. The VN and RLN also contribute to this plexus. The caudal limit of the thoracic cardiac nerves is the T5 ganglion, no contributions to the cardiac plexuses below this level were found. 
DE GAMA, B. Z.; LAZARUS, L.; PARTAB, P. \& SATYAPAL, K. S. Contribuciones simpáticas y parasimpáticas al plexo cardíaco: estudio fetal. Int. J. Morphol., 30(4):1569-1576, 2012.

RESUMEN: El plexo cardíaco está formado por los nervios simpáticos procedentes de los ganglios cervicales superior, medio e inferior o cervicotorácico, así como los ganglios torácicos desde el primero al quinto. Por otra parte, el nervio vago y su contraparte, el nervio laríngeo recurrente suministra al plexo cardíaco nervios cardíacos parasimpático. Esta investigación tuvo como objetivo revisar y registrar las contribuciones mediales de los ganglios cervicales, ganglios torácicos del primero al quinto ganglios y contribuciones mediales de los nervios laríngeos recurrentes y vagos en el plexo cardíaco. Se realizó la micro-disección bilateral de cuarenta especímenes cadavéricos fetales $(n=80)$. Los orígenes de las contribuciones simpáticas hacia el plexo cardíaco se describen de forma independiente como ganglionar o inter-ganglionar, o desde ambos ganglios y la cadena simpática interganglionar. El número de ganglios simpáticos cervicales varió de dos a cinco; el ganglio cervical superior fue constante, mientras que los ganglios medio-cervical, vertebral, cervical inferior o cervicotorácico fueron variables. La prevalencia de los nervios cardíacos fueron: nervio cardíaco cervical superior (95\%); nervio cardíaco cervical medio (73\%); nervio cardiaco vertebral (41\%); nervio cardíaco cervical inferior (21\%) y nervio cardíaco cervicotorácico (24\% ). La investigación registró el límite torácico caudal de las contribuciones torácicas simpáticos al plexo cardíaco como el ganglio T5. Los resultados de este estudio muestran la importancia de comprender las contribuciones simpáticas mediales y sus variaciones en el plexo cardíaco, ya que podrían ayudar a los cirujanos durante los procedimientos quirúrgicos mínimanente invasivos, simpatectomías, pericardiectomías y en el manejo de enfermedades como el fenómeno de Raynaud y la angina de pecho.

PALABRAS CLAVE: Plexo cardíaco; Simpático; Parasimpática; Nervio vago; Plexo cervical superficial; Plexo cervical profundo.

\section{REFERENCES}

Becker, R. F. \& Grunt, J. A. The cervical sympathetic ganglia. Anat. Rec., 127(1):1-14, 1957

Ellison, J. P. \& Williams, T. H. Sympathetic nerve pathways to the heart, and their variations. Am. J. Anat., 124(2):149-62, 1969.

Fukuyama, U. Macroscopic anatomy of the nerves innervating the human heart. Kaibogaku Zasshi., 57(5):357-80, 1982.

Groen, G. J.; Baljet, B.; Boekelaar, A. B. \& Drukker, J. Branches of the thoracic sympathetic trunk in the human fetus. Anat. Embryol. (Berl.), 176(4):401-11, 1987.

Hollinshead, H. W. Anatomy for Surgeons. $2^{\text {nd }}$ ed. New York, Harper and Row publishers Inc., 1968. pp.532-4.

Kadowaki, M. H. \& Levett, J. M. Sympathectomy in the treatment of Anginas and Arrythmias. Ann. Thorac. Surg., 41(5):572-8, 1986.

Kalsey, G.; Mukherjee, R. N. \& Patnaik, V. V. G. A comparative study of the cervical sympathetic chain. J. Anat. Soc. India, 49(1):26-30, 2000.

Kawashima, T. The autonomic nervous system of the human heart with special reference to its origin, course and peripheral distribution. Anat. Embryol. (Berl.), 209(6):425-38, 2005.

Khogali, S. S.; Miller, M.; Rajesh, P. B.; Murray, R. G. \& Beattie, J. M. Video-assisted thoracoscopic sympathectomy for severe intractable angina. Eur. J. Cardiothorac. Surg., 16(Suppl. 1):595-8, 1999.

Kuntz, A. \& Morehouse, A. Thoracic sympathetic cardiac nerves in man. Arch. Surg., 20(4):607-13, 1930.

Mitchell, G. A. G. Anatomy of the autonomic nervous system. Edinburgh, London, Livingstone LTD, 1953.

Mizeres, N. J. The cardiac plexus in man. Am. J. Anat., 112:141-51, 1972.

Pather, N.; Partab, P.; Singh, B. \& Satyapal, K. Cervico-thoracic ganglion: Its clinical implications. Clin. Anat., 19(4):323-6, 2006.

Pather, N.; Partab, P.; Singh, B. \& Satyapal, K. S. The sympathetic pathways to the cardiac plexus. Surg. Radiol. Anat., 25(3-4):210-5, 2003.
Perman, E. Anatomische Untersuchungen über die Herznerven bei den höheren Saugetieren und beim Menschen. Z. Anat. Entwicklungsgesch., 71(4-6):382-457, 1924.

Randall, W. C. \& Armour, J. A. Neural regulation of the heart. New York, Oxford University Press, 1977. pp.13-41. Chapter 2.

Rathinam, S.; Nanjaiah, P.; Sivalingam, S. \& Rajesh, P. B. Excision of sympathetic ganglia and the rami communicantes with histological confirmation offers better early and late outcomes in Video assisted thoracoscopic sympathectomy. J. Cardiothorac. Surg., 3:50, 2008.

Romanes, G. J. Cunningham's Manual for Practical Anatomy. $13^{\text {th }}$ ed. London, Oxford University Press, 1968. pp.29-39, 49,75-6. Vol. 2.

Saccomanno, G. The components of the upper thoracic sympathetic nerves. J. Comp. Neurol., 79(3):355-78, 1943.

San Mauro, M. P.; Patronelli, F.; Spinelli, E.; Cordero, A.; Covello, D. \& Gorostiaga, J. A. Nerves to the heart: a comprehensive review with a clinical point of view. Neuroanatomy, 8:26-31, 2009.

Standring, S. An anatomical basis for clinical practice. $40^{\text {th }}$ ed. London, Churchill Livingstone, 2008. pp.235-8, 253-7, 559-60, 1019-20.

Zhang, B.; Li, Z.; Yang, X.; Li, G.; Wang, Y.; Cheng, J. \& Wang, F. Anatomical variations in the upper thoracic sympathetic chain. Clin. Anat., 22(5) :595-600, 2009.

\section{Correspondence to:}

Professor K. S. Satyapal

Department of Clinical Anatomy

School of Laboratory Medicine and Medical Sciences

College of Health Sciences

University of KwaZulu-Natal

Private Bag X54001

Durban, 4000

SOUTH AFRICA

Telephone number: + 27312607298 ;

+ 27837778780

Email: satyapalk@ukzn.ac.za

Received: 16-07-2012

Accepted: 10-08-2012 